\title{
EXPERIENCE AT HAMMERSMITH HOSPITAL WITH CARDIOPULMONARY BY-PASS OPERATIONS IN CHILDREN*
}

\author{
BY \\ BLANCA SMITH† \\ From the Cardio-Thoracic Unit of the Department of Surgery, Postgraduate Medical School of London
}

During the five-year period July 1957 to June 1962, 229 children with cardiac anomalies underwent surgical correction aided by cardiopulmonary bypass in the Cardio-Thoracic Unit of the Hammersmith Hospital. This report includes only patients up to 14 years of age, and outlines the diagnostic and pre-operative measures as well as the surgical and perfusion techniques used. Details of the postoperative management and the results are also discussed.

\section{Diagnosis}

Children with suspected cardiac malformations are in the first instance referred to the Cardiology Department and subsequently admitted for complete investigation. The following tests are conducted routinely in addition to a thorough physical examination: chest radiographs, electro- and phonocardiograms, ear oximetry and right heart catheterization. The angiographic techniques are carried out in conjunction with the Department of Diagnostic Radiology.

Great care is taken to assess the degree of pulmonary vascular disease suggested by the physical findings. For confirmation the pulmonary artery resistance is measured at catheterization taking into account the response to acetylcholine vasodilatation. The pulmonary vessels are examined further by selective angiography and wedge arteriograms with injection of contrast medium into a segmental pulmonary vessel.

Selective right or left angiocardiography is carried out in the majority of patients with intracardiac pathology, except those with an uncomplicated atrial septal defect of the secundum type. During right heart catheterization, the left side of the heart is almost invariably entered should an atrial

* A paper read at a meeting of the British Association of Paediatric Surgeons in London, September 1962.

$\dagger$ Present address: Assistant Professor, Department of Surgery, Ohio State University and The Children's Hospital, Columbus, Ohio, U.S.A. septal defect exist. For assessment of aortic and mitral incompetence, however, retrograde techniques are preferred. An accompanying patent ductus arteriosus is always borne in mind, and if suspected it is sought for on a retrograde aortogram. Transseptal catheterizations are reserved for measurement of aortic gradients and left ventricular angiocardiography. It is usually possible to perform these diagnostic procedures under sedation and local anaesthesia only.

When the investigations are completed the patient with the pertinent diagnostic data is presented to the weekly Joint Cardiac Clinic of the Surgical and Medical Staff, and the future management is discussed. The decision to defer surgery until a later date, to operate in the near future or not to operate at all is entered in the patient's records.

In those patients in whom operation is deferred, further dates for reassessment are booked. Amongst these are, for example, symptomless children under 6 years of age, with a small ventricular septal defect, normal pulmonary resistance and ratio of pulmonary to systemic circulation less than 1.5 to 1 . Surgery is also deferred in asymptomatic patients with minimal pulmonary or aortic stenosis without evidence of hypertrophy of the respective ventricles. In these cases surgery will be advised if at future revisions symptoms are found to have developed, or clinical proof of progressive pathology becomes evident.

The presence of a pulmonary vascular resistance over five units would make surgery for an atrial septal defect inadvisable. Fortunately this situation is uncommon in childhood. A ventricular septal defect is placed among the inoperable group only when the shunt has balanced or reversed and the high pulmonary resistance cannot be lowered by acetylcholine-induced vasodilatation. But while some degree of left-to-right shunting is still present, closure of the defect will be undertaken in spite of the pulmonary hypertension. The risks are therefore proportionally higher. Complete correction of 
a Fallot's tetralogy is normally carried out in one stage. Marked hypoplasia of the pulmonary artery, however, contraindicates the one-stage repair. In these cases closure of the ventricular septal defect would be preceded by a transventricular relief of the pulmonary outflow obstruction. An increase in the calibre of the pulmonary artery is expected to follow. Occasionally a proximal pulmonary atresia with good calibre of the right pulmonary artery distally, makes the candidate suitable for a Glenn (1958) type of anastomosis. Tricuspid atresia is another indication for this right pulmonary artery superior vena cava shunt. In anomalies carrying an almost prohibitive surgical risk such as complete A-V canal, double outlet right ventricle and single ventricle, surgery is considered only if the severity of the symptoms justifies it.

If the patient is accepted for surgery the relative urgency of the operation is discussed, and a priority code number is assigned to each case on the waiting list, guaranteeing that top priority cases are called in for surgery as soon as possible.

During this admission a search is made to rule out the presence of sources of infection in tonsils, ears or urinary tract. The condition of the teeth is determined and any necessary dental extractions are done under antibiotic cover, either then, or several weeks at least before readmission for cardiac surgery. Before discharge the Blood Transfusion Department performs routine blood grouping and detailed screening for antibodies.

\section{Pre-operative Measures}

The child is readmitted as a surgical patient four to five days before the scheduled date of operation. Chest radiograph, ear oximetry and electro- and phonocardiograms are repeated. The patient is visited by the medical staff, and his case may be discussed again at the Joint Cardiac Clinic if there have been any important developments since his original evaluation.

A full blood picture is obtained as well as determination of blood urea and electrolytes. The following screening tests to rule out any bleeding tendencies or coagulation defects are conducted in all patients, i.e. recalcification time, one-stage Quick's prothrombin time, platelet count and Hick's modification of the thromboplastin generation test. If any abnormalities are detected, additional tests specific for the defect suspected are carried out. In some of the severely cyanotic children with haematocrit levels over $70 \%$, attempts are made to lower them by repeated exchange transfusions of plasma. Not more than $15 \%$ of the blood volume is exchanged at any one time.
During the intervening days before operation a definite effort is made to help the child to get acquainted with the routines, and the medical and nursing personnel. Practice sessions in respiratory exercises are conducted twice daily in the ward by the same physiotherapist who will take charge of the child after operation. New patients and convalescents frequently join in. An old oxygen tent is available in the playroom for the children to become familiar with its appearance. As far as possible the child's doubts about being anaesthetized are dispelled by a visit from the anaesthetist who explains in simple language what the child should expect. The Sister in charge of the Recovery Ward also visits so that her face will be familiar when the child wakes in the new surroundings of the Recovery Ward. Recent body weight, height and surface area are among the essential data in the case notes that accompany the patient to the theatre. Details of the anaesthetic techniques employed at the present time are given by Beard (1963).

\section{Surgical and Perfusion Techniques}

Being so closely related, they will be commented upon in the approximate order in which they take place.

The arterial pressure is monitored continuously through a catheter in the radial artery, usually the left. Catheters, passed via one of the external jugular veins into the superior vena cava and via the left saphenous vein into the inferior vena cava, are used to monitor the central venous pressure. Electrocardiogram and electro-encephalogram tracings are visible on the oscilloscopic screen and can be recorded when required. Oesophageal and rectal temperatures are measured by electric thermometers.

The skin from the neck to mid thigh is covered with a piece of thin plastic film (Vi-Drape) which is made to adhere with a 'spray-cement' (Vi-Adherent). This gives a large sterile field, impermeable to moisture for the duration of the procedure. The sternum is split vertically, after exposure through a vertical skin incision in boys, and a low lying transverse incision in girls. Entry into either pleural cavity is avoided. Inspection of the heart to determine the size of the chambers and calibre of the great vessels follows. Atrial and ventricular pressures are measured and recorded as are PA or aortic pressures where relevant. Digital exploration of the right atrium may be carried out at this stage. The absence of a patent ductus or anomaly of the venous drainage is also ascertained. Earlier in the series unsuspected patent ductus arteriosus made 
perfusion impossible in three patients. If the patient has tetralogy of Fallot with a previous shunt of the Blalock-Taussig type, access is gained to the site of the anastomosis by dissecting over the arch of the aorta until the origin of the subclavian artery is reached. A ligature is placed around it, which is tied just before by-pass is begun.

The Melrose NEP disc oxygenator has been used in all cases. The blood for priming is collected into Edgludate on the day before operation. $15 \mathrm{mg}$. of bacteriostat-free heparin is injected into the oxygenator for each pint of blood used. The mixture is then recalcified allowing $180 \mathrm{mg}$. of $\mathrm{CaCl}_{2}$ per pint. During the past year $20 \mathrm{ml} . / \mathrm{kg}$. body weight of low molecular weight dextran (Rheomacrodex) has been added to the blood in the oxygenator. This has reduced the amount of donor blood required for priming and maintained the haematocrit within the normal range while increasing the urinary output (Martinovic and Melrose, 1962). The flow-rate from the oxygenator is calculated to give the patient $2.41 . / \mathrm{min} . / \mathrm{m}^{2}$ surface area. The technique established by Melrose for achieving a 'physiologically undetectable' perfusion is followed, maintaining a preselected arterial inflow while preserving a constant pressure in the central venous system. This is achieved by determining from the flow chart (Table 1) the femoral cannula that will ensure the appropriate arterial flow for the surface area of the patient and deliver it at the required pressure. Suitable caval catheters are chosen from the same flow chart to provide adequate venous drainage.

The operating table is adjusted to a differential height of 30 in. $(76 \cdot 2 \mathrm{~cm}$.) above the oxygenator. The caval catheters used are made of nylon and are introduced into each cava by separate incisions in the right atrium. The femoral artery cannula is made of stainless steel and is straight. It is usually inserted into the left femoral artery. The administration of $3 \mathrm{mg} . / \mathrm{kg}$. heparin immediately precedes cannulation of the vessels. A further half dose is given at hourly intervals thereafter during the perfusion. When the by-pass circuit is established the desaturated blood from the cavae flows by gravity into the oxygenator. After being oxygenated the blood is pumped through a heat exchanger and a combined filter and bubble trap and thence to the femoral artery. An adjustable screw clamp in the venous line is used to regulate the venous return to the machine, keeping the venous pressure constant and automatically balancing the arterial inflow with the venous return. During most of the perfusions the blood is cooled to approximately $30^{\circ} \mathrm{C}$. by the heat exchanger.
TABLE 1

A GUIDE TO PERFUSIONS ON BASIS OF SURFACE AREA OF PATIENTS

\begin{tabular}{|c|c|c|c|c|}
\hline $\begin{array}{c}\text { Surface } \\
\text { Area } \\
\left(\mathrm{m} .{ }^{2}\right)\end{array}$ & $\begin{array}{l}\text { Output } \\
\text { From } \\
\text { Pump } \\
\text { (ml.) }\end{array}$ & $\begin{array}{c}\text { Internal } \\
\text { Diameter } \\
\text { of } \\
\text { Cannula } \\
(\mathrm{mm} .)\end{array}$ & $\begin{array}{c}\text { Pressure } \\
\text { Created } \\
\text { by } \\
\text { Cannula } \\
(\mathrm{mm} . / \mathrm{Hg})\end{array}$ & $\begin{array}{c}\text { Venous } \\
\text { Catheter } \\
\text { Internal } \\
\text { Diameter } \\
\text { (mm.) }\end{array}$ \\
\hline $\begin{array}{l}0.4 \\
0.5 \\
0.6 \\
0.7 \\
0.8 \\
0.9 \\
1 \cdot 0 \\
1 \cdot 2 \\
1.4 \\
1.6 \\
1.8 \\
2.0 \\
2.2\end{array}$ & $\begin{array}{r}960 \\
1,200 \\
1,440 \\
1,680 \\
1,920 \\
2,160 \\
2,400 \\
2,880 \\
3,360 \\
3,840 \\
4,320 \\
4,800 \\
5,280\end{array}$ & $\begin{array}{l}- \\
3 \\
3 \\
3 \cdot 5 \\
3 \cdot 5 \\
4 \\
4 \\
4 \cdot 5 \\
4 \cdot 5 \\
5 \\
5 \cdot 5 \\
6\end{array}$ & $\begin{array}{r}- \\
75 \\
100 \\
75 \\
100 \\
70 \\
80 \\
75 \\
100 \\
100 \\
90 \\
85\end{array}$ & $\begin{array}{l}- \\
-4 \cdot 7 \\
4 \cdot 7 \\
5 \cdot 5 \\
5 \cdot 5 \\
5 \cdot 5 \\
6 \cdot 3 \\
6 \cdot 3 \\
6 \cdot 3 \\
7 \cdot 9 \\
7 \cdot 9 \\
7 \cdot 9\end{array}$ \\
\hline
\end{tabular}

Atrial septal defects and some ventricular septal defects may be accurately repaired with the heart beating. Brief periods of aortic cross-clamping may be required intermittently to improve visibility. For complicated defects or when bronchial flow is excessive, cardiac asystole is desirable. This is achieved by reducing the body temperature still further until the heart fibrillates and arrests, which is usually at about $27^{\circ} \mathrm{C}$.

Hypothermic arrest has replaced the chemical arrest used early in the series when the aorta was clamped and potassium citrate injected into it, proximal to the clamp. Prolonged aortic crossclamping is limited now to surgery of the aortic valve. In these cases the myocardium is further protected by additional direct cooling of the heart with saline slush into the pericardium, which reduces the myocardial temperature to approximately $14^{\circ} \mathrm{C}$. to $12^{\circ} \mathrm{C}$. For procedures lasting more than a few minutes the coronary arteries are perfused directly, but this is seldom necessary in congenital aortic stenosis. It is felt that avoidance of prolonged aortic cross-clamping with its consequent myocardial ischaemia has improved survival.

Another measure which has had a direct influence on the improvement of results is the technique now used to drain retrograde overflow from the left ventricle. The source of this overflow may be an incompetent aortic valve, or excessive bronchial flow from the pulmonary veins, as in Fallot's tetralogy. The influx of blood into the arrested heart results in overdistension of the left ventricle. The preventive measure used in the earlier cases was a small catheter introduced into the left atrial appendage. This has now been replaced by direct venting of the left ventricle with a large bore catheter which, because of its size and location can 
more adequately fulfil the purpose (El Sayed, Bentall and Melrose, 1962).

The left ventricular vent is inserted while the patient is in partial perfusion and cooling is proceeding, before the heart is arrested. The corrective part of the operation follows. Ventricular septal defects and pulmonary infundibular stenosis are corrected through a right ventriculotomy approach. The incision may be either vertical or transverse, as the anatomy of the coronary branches indicates. Septal defects are closed directly by sutures where possible or by a patch. In the early cases the material used for the patch was compressed 'ivalon' sponge. This has been replaced by 'teflon' felt. Pulmonary infundibular stenosis is now corrected by extensive infundibulectomy and release of tight trabeculae carnea, inserting outflow tract patches only when essential. The material used for the patch may be 'teflon' felt or pericardium, and extension across the pulmonary valve is avoided as much as possible. Pulmonary and aortic valvotomies are done under direct vision after exposing the valve through the incised vessel wall.

When a patch is used for repair of an atrial septal defect with associated cleft mitral valve (AV canal), the left atrial side of the patch is covered with a piece of pericardium. This prophylactic manoeuvre has been in use since two adult patients developed haemolytic anaemia following repair of an atrioventricular canal (Sayed, Dacie, Handley, Lewis and Cleland, 1961). It was thought that the patch was being exposed to a regurgitant jet of blood from residual mitral regurgitation, the trauma contributing to the haemolysis. The left atrial side of the patch was covered with pericardium at a second operation effecting dramatic cure of the haemolysis.

When the corrective part of the operation is near completion, rewarming of the patient is begun. Meanwhile, the cardiotomy or arteriotomy is closed. When hypothermic arrest has been used, spontaneous defibrillation usually occurs on rewarming. If it does not, defibrillation is generally achieved with a single shock of approximately 200 volts. The voltage is chosen according to the size of the child. With a regular rhythm restored, the heart takes over and perfusion is gradually slowed down and stopped. Diagnostic pressures are repeated and if they are satisfactory the cannulae are removed. If there is atrial ventricular dissociation, pacemaker wires are inserted into the myocardium.

The heparin is neutralized with protamine sulphate (6 $\mathrm{mg} . / \mathrm{kg}$. body weight). This drug is preferred as no appreciable decrease in post-operative bleeding was noted in the 50 cases who received hexadi- methrine bromide. The parallel between bleeding and abnormalities in clotting tests detected in 400 perfusions at Hammersmith Hospital will be the subject of a separate report. Careful attention is paid to haemostasis, and the chest is closed only after the surgeon is completely satisfied that the blood loss is under control. This attitude has greatly reduced the incidence of continued bleeding, necessitating re-exploration. The pericardium is only loosely approximated. Several large bore catheters connected to suction are used to drain the mediastinum, the pericardium, and the pleura if it has been opened. In patients with high pulmonary vascular resistance, elective tracheostomy may be performed at the conclusion of the operation. The patient is no longer weighed before and after perfusion as, using the described technique for perfusion management, the patient's blood volume is expected to be the same at the end of by-pass as it was at the beginning. All blood loss occurring during the chest closure is replaced before leaving the theatre and the chest tubes are clamped while the patient is taken to the recovery ward.

\section{Post-operative Management}

This is carried out in a recovery ward suitably equipped and staffed for the intensive care that these cases need. As soon as the patient arrives in the ward the chest tubes are unclamped and 'milked' vigorously. This manoeuvre is repeated frequently, and every 15 minutes a meticulous record of blood loss is recorded on a large wall chart (Table 2). The saphenous vein catheter is connected to a manometer and frequent determinations of the inferior vena cava pressure are used as criterion for blood replacement. The possibility of tamponade is always kept in mind during the first 24 hours after operation.

The haematocrit is given special attention, particularly in patients with tetralogy of Fallot. The arterial blood $p \mathrm{H}$, standard bicarbonate, $\mathrm{PCO}_{2}$ and oxygen saturation, which have been checked at regular intervals during perfusion and before leaving the theatre, are followed by frequent determinations during the post-operative period. The radial artery catheter is left in situ for 24 to $\mathbf{4 8}$ hours. There is a small laboratory adjacent to the recovery ward and a technician who carries out the determinations. Metabolic acidosis is treated with $4 \cdot 2 \% \mathrm{NaHCO}_{3}$. Except when conduction disturbances exist all patients who have had a ventriculotomy are digitalized, starting during or shortly after operation.

A chest radiograph is obtained on arrival in the recovery ward and physiotherapy is instituted soon afterwards and repeated at four-hourly intervals. 
TABLE 3

CONGENITAL HEART DISEASE IN CHILDREN : OPERATIONS UNDER PERFUSION (Hammersmith Hospital, July 1957-June 1962)

\begin{tabular}{|c|c|c|c|}
\hline Defect & $\begin{array}{c}\text { No. of } \\
\text { Cases }\end{array}$ & Alive & Dead \\
\hline $\begin{array}{l}\text { Ventricular septal defect } \\
\text { Tetralogy of Fallot } \quad \ldots\end{array}$ & $\begin{array}{r}111 \\
42 \\
28 \\
19 \\
16 \\
5 \\
8\end{array}$ & $\begin{array}{r}98 \\
30 \\
27 \\
9 \\
15 \\
5 \\
5\end{array}$ & $\begin{array}{r}13 \\
12 \\
1 \\
10 \\
1 \\
0 \\
3\end{array}$ \\
\hline Total .. & 229 & 189 & 40 \\
\hline
\end{tabular}

The Department of Anaesthetics co-operates closely in the management of respiratory complications. Tracheostomy and intermittent positive pressure breathing treatment have been life-saving in some cases.

Intravenous fluids are given at a rate of 1,200 $\mathrm{ml} . / \mathrm{m} .{ }^{2} / 24$ hours. An oesophagastric tube is kept in situ for approximately 12 hours. It is removed when bowel sounds are heard. Most of the patients tolerate oral fluids well in 24 hours and take solids the next day. Determinations of blood urea, electrolytes and platelet counts are performed daily for the first three days, which is the average length of stay in the recovery ward. A slight drop in the platelet count is usual. The patients are sat up on the fourth or fifth day and are usually ambulant by the fourteenth day.

\section{Results}

The series includes all children under 15 years of age who were operated upon with the aid of cardiopulmonary by-pass between July 1957 and June 1962 . The distribution of cases according to diagnosis and the number of deaths are seen in Table 3.

Ventricular Septal Defects. It is a well-established fact that the degree of pulmonary hypertension determines the operative risk. Among the 111 patients operated upon during the five-year period, there were 33 with a pulmonary vascular

TABLE 4

VENTRICULAR SEPTAL DEFECTS (111 cases) RESULTS RELATED TO PULMONARY VASCULAR RESISTANCE

\begin{tabular}{|c|c|c|c|c|}
\hline \multirow{2}{*}{ Resistance } & \multicolumn{2}{|c|}{$1957-1962$} & \multicolumn{2}{|c|}{ 1960-1962 } \\
\hline & Total & Mortality & Total & Mortality \\
\hline 1 to 8 units & 78 & $(8 \cdot 3 \%)$ & 47 & $(\overline{0 \%})$ \\
\hline Over 8 units & 33 & $\begin{array}{c}7 \\
(21 \cdot 2 \%)\end{array}$ & 19 & $\begin{array}{c}5 \\
(26 \%)\end{array}$ \\
\hline
\end{tabular}

resistance above 8 units (normal 0-2 units) (Wood, 1952); the mortality was $21 \cdot 2 \%$, while in the remaining 78 patients with normal or only mild pulmonary hypertension, the mortality was $8.3 \%$.

Comparing in Table 4 the results of the whole series with those obtained since 1960, the difference is further emphasized. There were no deaths among the 47 patients without pulmonary hypertension operated upon since January 1960, in spite of 19 of them having had simultaneous correction of associated cardiac anomalies. The mortality mounted, however, to $26 \%$ among the 19 patients with pulmonary vascular resistance above 8 units. Of the five patients who died, four also had associated defects.

Tetralogy of Fallot. The average mortality after operation for complete correction was $28.5 \%$ among 41 patients, most of whom were cyanotic. Among those cyanotic patients who have had a previous shunt, the survival rate was slightly better, in spite of the operation being more complicated. This is in agreement with the experience reported by others (Kirklin, Payne, Theye and DuShane, 1960). In the acyanotic group the survival rate after complete correction is considerably better. There was only one death among the 11 acyanotic Fallots operated upon since 1960.

Pulmonary Stenosis. Of the 28 cases, only one patient died, the first of the series.

Ostium Primum and AV Canal (19 cases). The mortality in this highly complicated group of endocardial cushion defects has been $52 \%$ for the series as a whole. Considering only cases operated upon since 1960 , the mortality rate has reduced to $20 \%$.

Aortic Stenosis (16 cases). As in pulmonary stenosis, the only death was early on in the series.

Atrial Septal Defects. There were no deaths among the five patients who had repair of atrial septal defects of the secundum type, either under by-pass or hypothermia. Those done under hypothermia are not included in this report.

Miscellaneous Anomalies. Of the eight patients, three patients who died had the following anomalies: complete transposition of the great vessels, tricuspid incompetence and 'double outlet right ventricle', respectively. Two other patients who had 'double outlet' right ventricle were corrected successfully. The other survivors in this group included a patient with a single ventricle, one with an aortic/pulmonary 
window and a child with absent aortic arch in whom a 'teflon' graft was inserted under left heart by-pass.

\section{Summary}

The diagnostic, surgical and perfusion techniques used at present in Hammersmith Hospital have been discussed. The report is confined to children under 15 years of age, who were operated upon with the aid of cardiopulmonary by-pass between July 1957 and June 1962.

The changes that have been introduced since the techniques previously reported from this Unit (Cleland, Beard, Bentall, Bishop, Baimbridge, Bromley, Goodwin, Hollman, Kerr, Lloyd-Jones, Melrose and Telivuo, 1958) have been stressed.

The results obtained during the past two years are compared with those in the earlier part of the series.

Grateful acknowledgement is given to Dr. J. F. Goodwin, Dr. A. Hollman, and the Department of Medicine; to Professor R. E. Steiner and the Department of Diagnostic Radiology; to Dr. A. J. W. Beard, Dr. E. B. Lloyd-Jones, Dr. M. K. Sykes and the Department of Anaesthetics and to the Department of Surgery, particularly to Mr. W. P. Cleland, Mr. H. H. Bentall and Dr. D. G. Melrose, whose patients are the subject of this report.

\section{REFFRENCES}

Beard, A. J. W. (1963). In Thoracic Anaesthesia, ed. W. Mushin. Blackwell, Oxford

Cleland, W. P., Beard, A. J. W., Bentall, H. H., Bishop, M. B., Baimbridge, M. V., Bromley, L. L., Goodwin, J. F., Hollman, A., Kerr, W. F., Lloyd-Jones, E. B., Melrose, D. G. and Telivuo, L. J. (1958). The treatment of ventricular septal defect. Brit. med. J., 2, 1369.

El Sayed, H., Bentall, H. and Melrose, D. (1962). The tetralogy of Fallot. A new approach to complete correction. Lancet, 1, 549 .

Glenn, W. W. L. (1958). Circulatory bypass of the right side of the heart. IV. Shunt between superior vena cava and distal right pulmonary artery. Report of clinical application. New Engl. J. Med., 259, 117.

Kirklin. J. W., Payne, W. Spencer, Theye, R. A. and DuShane, J. W. (1960). Factors affecting survival after open operation for tetralogy of Fallot. Ann. Surg., 152, 485.

Martinovic, N. and Melrose, D. G. (1962). The use of low molecular weight dextran in extracorporeal circulation. Reported at the European Cardiovascular Congress, Stockhoim.

Sayed, H. M., Dacie, J. V., Handley, D. A.. Lewis, S. M. and Cleland, W. P. (1961). Haemolytic anaemia of mechanical origin after open heart surgery. Thorax, 16, 356.

Wood, P. (1952). Pulmonary hypertension. Brit. med. Bull., 8, 348 . 